\title{
LETTER
}

\section{Pulmonary vascular permeability index should not be called extravascular lung water pulmonary blood volume ratio}

\author{
Francois G Brivet ${ }^{* 1,2}$ \\ See related research by Chew et al., http://ccforum.com/content/16/1/R1
}

In their recent paper, Michelle Chew and colleagues [1] evaluated the performance accuracy of three extravascular lung water (EVLW) ratios in patients with shock at risk for or with acute lung injury (ALI). They indexed EVLW to actual body weight (ABW), predicted body weight (PBW) and pulmonary blood volume (PBV), and confirmed that all EVLW ratios were higher in patients with ALI and in non-survivors and correlated with respiratory parameters.

Although these findings are interesting, they deserve some comments. First, whereas indexing EVLW to PBW may reduce the number of patients with acute respiratory distress syndrome (ARDS) with normal EVLW, in this population, the EVLW/ABW index performed best [2]. Furthermore, the absence of a link between EVLW and $\mathrm{PaO}_{2} / \mathrm{FiO}_{2}$ (calculated $\mathrm{r} 2$ of 0.14 to 0.23 ) could explain that these indices identified only 33\% of ALI and 38\% of ARDS cases. Second, the EVLW/PBV terminology appears very unusual. The transpulmonary thermodilution technique determines cardiac output, intrathoracic thermal volume (ITTV), pulmonary thermal volume (PTV) and global end-diastolic volume (Global end-diastolic volume $($ GEDV $)=$ ITTV - PTV $)$. The estimated blood volume of the chest (Intrathoracic blood volume (ITBV) $=$ GEDV + PBV) permits the calculation of PBV (ITBV $=1.25 \times$ GEDV - $28.4 \mathrm{ml}$ ) [3]. Importantly, the PiCCO monitor automatically provides, at each calibration, an estimation of the pulmonary vascular permeability index (PVPI), based on the ratio of EVLW to PBV, which reflects alveolar-capillary barrier permeability and is of importance for the mechanisms of pulmonary edema $[4,5]$.

*Correspondence: francois.brivet@gmail.com

'Service de Réanimation Médicale, Hôpital Antoine Béclère, Hôpitaux universitaires Paris Sud, APHP, Clamart F 92140, France

¿Université Paris XI, Faculté de médecine Paris Sud, EA 4046, Le Kremlin Bicêtre, F 94270, France
Thus, I believe that it would be more pertinent to use the PVPI instead of the EVLW/PBV ratio and that it is time to promote an international consensus on this.

\section{Abbreviations}

ABW, actual body weight; ALI, acute lung injury; ARDS, acute respiratory distress syndrome; EVLW, extravascular lung water; GEDV, global end-diastolic volume; ITBV, intrathoracic blood volume; ITTV, intrathoracic thermal volume; PBV, pulmonary blood volume; PBW, predicted body weight; PVPI, pulmonary vascular permeability index.

\section{Competing interests}

The author declares that they have no competing interests.

Published: 14 March 2012

\section{References}

1. Chew MS, Ihrman L, During J, Bergenzaum L, Ersson A, Unden J, Ryden J, Akerman E, Larsson M: Extravascular lung water index improves the diagnostic accuracy of lung injury in patients with shock. Crit Care 2012, 16:R1.

2. Michard F, Phillips C: Measuring extravascular lung water (and derived parameters) in patients with acute respiratory distress syndrome: what's right, what's wrong, and what's ahead? Crit Care Med 2009, 39:2118-2119.

3. Sakka SG, Rühl CC, Pfeiffer UJ, Beale R, McLuckie A, Reinhart K, MeierHellmann A: Assessment of cardiac preload and extravascular lung water by single transpulmonary thermodilution. Intensive Care Med 2000, 26:180-187.

4. Monnet X, Anguel N, Osman D, Hamzaoui O, Richard C, Teboul JL: Assessing pulmonary permeability by transpulmonary thermodilution allows differentiation of hydrostatic edema from ALI/ARDS. Intensive Care Med 2007, 33:448-453.

5. van der Heijden M, Groeneveld ABJ: Extravascular lung water to blood volume ratios as measures of pulmonary capillary permeability in nonseptic critically ill patients. J Crit Care 2010, 25:16-22.

doi:10.1186/cc11208

Cite this article as: Brivet FG: Pulmonary vascular permeability index should not be called extravascular lung water pulmonary blood volume ratio. Critical Care 2012, 16:417. 